\title{
Greenhouse gas emissions during plantation stage of palm oil-based biofuel production addressing different land conversion scenarios in Malaysia
}

\begin{abstract}
The environmental impacts with regard to agro-based biofuel production have been associated with the impact of greenhouse gas (GHG) emissions. In this study, field GHG emissions during plantation stage of palm oil-based biofuel production associated with land use changes for oil palm plantation development have been evaluated. Three different sites of different land use changes prior to oil palm plantation were chosen; converted land-use (large and small-scales) and logged-over forest. Field sampling for determination of soil Nmineralisation and soil organic carbon (SOC) was undertaken at the sites according to the age of palm, i.e. $<5$ years (immature), 5-20 and >21 years (mature oil palms). The field data were incorporated into the estimation of nitrous oxide $\left(\mathrm{N}_{2} \mathrm{O}\right)$ and the resulting $\mathrm{CO}_{2}$-eq emissions as well as for estimation of carbon stock changes. Irrespective of the land conversion scenarios, the nitrous oxide emissions were found in the range of $6.47-7.78 \mathrm{~kg} \mathrm{~N}_{2} \mathrm{O}-\mathrm{N} / \mathrm{ha}$ resulting in

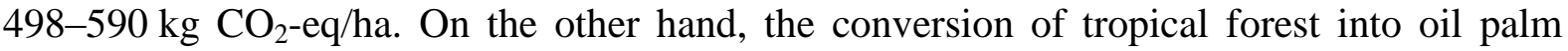
plantation has resulted in relatively higher GHG emissions (i.e. four times higher and carbon stock reduction by $>50 \%$ ) compared to converted land use (converted rubber plantation) for oil palm development. The conversion from previously rubber plantation into oil palm plantation would increase the carbon savings (20\% in increase) thus sustaining the environmental benefits from the palm oil-based biofuel production.
\end{abstract}

Keyword: Oil palm; Carbon stocks; Greenhouse gases; Nitrous oxide; Soil organic carbon; Biofuel 